RESEARCH PAPER RP1247

Part of Journal of Research of the National Bureau of Standards, Volume 23, October 1939

\title{
DETERMINATION OF OPTIMUM VOLTAGE FOR AIRPLANE ELECTRIC SYSTEMS
}

\author{
By Vernon H. Grant ${ }^{1}$ and Melville F. Peters
}

\section{ABSTRAC'T}

The standardization of aircraft equipment is desirable when such standardization does not interfere with efficient operation. The present paper deals with equations which have been developed for the standardization of electric equipment, and which indicate that the voltage for a large number of airplanes using storage batteries to carry peak loads can be advantageously standardized at 24 volts.

\section{CONTENTS}

I. Introduction

II. Development of equations for optimum voltage

III. Computations .

IV. Determination of optimum voltage for five airplanes

V. Changes in optimum voltages with $K_{2} \ldots$

VI. Discussion of results

VII. Conclusions

\section{INTRODUCTION}

Of the multitude of research problems involved in adapting complete electric systems to a basis of minimum weight for a required job, the fundamental problem is that of the characteristics of the powersupply system. At present, direct-current generators in parallel with lead-acid storage batteries provide an acceptable source of electric power in all but the largest airplanes.

The wiring installation of a military or transport airplane consists of insulated copper conductors of various sizes (No. 20 to No. 00 $A W G$ ) enclosed in hin-walled rigid or flexible aluminum conduit, with junction boxes, fittings, and other parts forming a complete metal-enclosed system. The remaining equipment, including generators, batteries, motors, lights, solenoids, radio transmitters and receivers, heating units, and other devices is usually constructed according to fundamentally conventional designs and is used in all classes of airplanes.

The earlier types of airplanes carried little electric equipment and the use of 12 volts as standard by the service was satisfactory. With increase in size and the requirement of better performance in all classes of airplanes, there has been a considerable increase in weight of the electric equipment, so that the determination of the optimum voltage, which is the voltage for which the weight of electric equipment is a minimum, has become of paramount importance. Calcu-

\footnotetext{
1 Engineer, Bureau of Aeronautics, United States Navy.
} 
lations were made to determine this optimum voltage. These calculations were long and tedious, since they required a calculation of the weight of the electric system for several voltages. The curve of weight versus voltage based on these calculations indicated that there was a voltage for which the weight was a minimum and that there was a considerable range of voltage over which the weight was very little more than the minimum. This range will be referred to as the minimum region. In making these calculations, certain assumptions had to be made as to the manner in which the weight of the component parts of the system changed with voltage. It was found that by making slight modifications in these assumptions they could be expressed in mathematical form. The analysis which follows shows how the equations used to express these assumptions lead to equations which give the optimum voltage and the minimum region in terms of certain constants associated with the weight of the electric equipment.

Application is made of these equations to existing airplane electric systems to show how their use faciitates the selection of the optimum voltage.

This work was done at the National Bureau of Standards and sponsored by the Bureau of Aeronautics, United States Navy Department.

\section{DEVELOPMENT OF EQUATIONS FOR OPTIMUM VOLTAGE}

The following treatment of the effect of voltage on the weight of the system is developed after assuming that the weight of the component parts changes with voltage in the following manner:

1. The weights of generators and load equipment (motors, lights, and several other units) are approximately independent of voltage.

2 . The weight of a storage battery for a given watt-hour capacity is made up of a constant plus a quantity $K_{2} E$, which is a direct function of the number of cells and hence indirectly a function of voltage (see eq 1).

3 . The weight of cable and conduit is assumed to be related to the voltage as given in $3 \mathrm{~A} 1,3 \mathrm{~A} 2,3 \mathrm{~A} 3 ; 3 \mathrm{~B} 1,3 \mathrm{~B} 2$; and $3 \mathrm{C} 1$.

$3 \mathrm{~A} 1$. The weight of conductor varies inversely as the square of the voltage except that portion under $3 \mathrm{~A} 3$.

$3 \mathrm{~A} 2$. The weight of conduit and insulation varies inversely as the voltage over the voltage range considered.

$3 \mathrm{~A} 3$. A certain weight of cable and conduit is independent of the voltage.

$3 \mathrm{~B}$. The weight of conductor varies inversely as the square of the voltage.

3B2. The weight of conduit and insulation varies inversely as the voltage.

3C1. The weight of cable and conduit varies inversely as the square of the voltage.

Within the voltage range considered safe for airplane operation, the independence of the weight of generator and load equipment stated with voltage, as under 1 , is sufficiently correct for all practical purposes. For lights, switches, fuses, and other small parts, the change in weight with voltage is slight, and in this voltage range the changes may be neglected. 
In private communications to the authors, C. B. Mirick, of the Naval Research Laboratory, and H. D. Wilson, of the Auto-Lite Co., have shown that to a close approximation the change in weight of storage batteries of a given type with voltage for a given watt-hour capacity may be represented by eq 1 . Their calculations were made for voltages from 6 to 48 . In figure 1 are shown changes in weight of storage batteries with voltage for $1 / 2-$ and $1-\mathrm{kw}$. output for periods of 5 and 20 minutes, respectively. The data were based on batteries now in the service.

The range of $K_{2}$ for these batteries is from 0.6 to 0.85 . In earlier types of aircraft batteries, $K_{2}$ was found to lie between 1.35 and 1 pound per volt, for the outputs shown in figure 1. The latter value

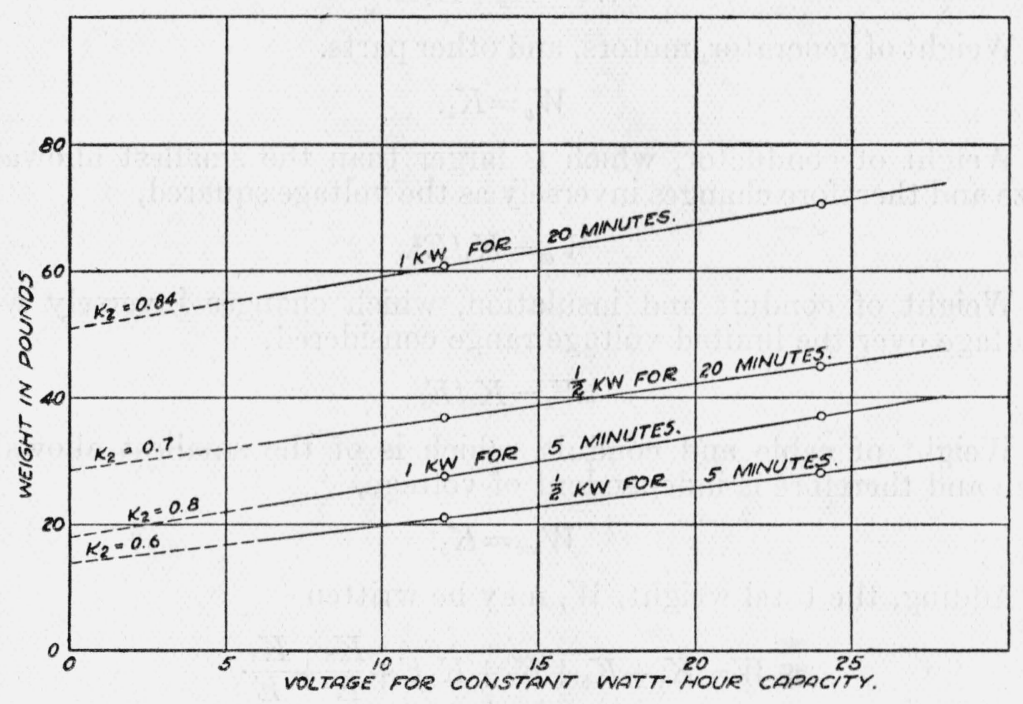

Figure 1.

Curves for batteries showing change in weight with voltage for the outputs indicated.

$W_{b}=K_{o}+K_{2} E$

was used in a number of the earlier calculations, and some of the results are given here, using $K_{2}=1$ instead of $K_{2}=0.85$.

$K_{2}$ changes with the watt-hour capacity of the battery but not with the voltage, and so may be regarded as a constant in subsequent differentiation with respect to voltage.

Assumption $3 \mathrm{~A} 1$ is strictly true if for each voltage the size of the conductor is selected so as to keep the percentage voltage drop constant.

Assumption $3 \mathrm{~A} 2$ states that the weight of conduit and insulation changes inversely with the voltage. A more exact equation would indicate the cross-sectional area of the insulation, and the conduit would change with the average radius multiplied by the thickness. Since the thickness of the insulation of the cable does not increase uniformly with the size of the conductor, but with groups of sizes, an equation which would exactly express the relationship between weight of insulation and size of cable is beyond the scope of this inves- 
tigation. As will appear later, little difference is obtained in optimum voltage whether this assumption or $3 \mathrm{C} 1$ is used.

Assumption $3 \mathrm{~A} 3$ is made because in many types of airplanes there are low-candlepower lights, indicating devices, and other equipment which require such small currents that mechanical strength limits the size of the conductor rather than the electric resistance.

Assumptions $3 \mathrm{~B} 1$ and $3 \mathrm{~B} 2$ are not as close an approximation to the actual relationship between weight and voltage as $3 \mathrm{~A} 1,3 \mathrm{~A} 2,3 \mathrm{~A} 3$; and $3 \mathrm{C} 1$ is not as close as $3 \mathrm{~B} 1$ and $3 \mathrm{~B} 2$.

The weight of the electric equipment of any one airplane, according to assumptions $3 \mathrm{~A} 1,3 \mathrm{~A} 2$, and $3 \mathrm{~A} 3$, may be stated as follows:

Weight of batteries,

$$
W_{b}=K_{0}+K_{2} E .
$$

Weight of generator, motors, and other parts.

$$
W_{o}=K_{1} \text {. }
$$

Weight of conductor, which is larger than the smallest allowable size and therefore changes inversely as the voltage squared,

$$
W_{w}=K_{3} / E^{2} \text {. }
$$

Weight of conduit and insulation, which changes inversely with voltage over the limited voltage range considered,

$$
W_{c}=K_{4} / E \text {. }
$$

Weight of cable and conduit, which is of the smallest allowable size and therefore is independent of voltage,

$$
W_{w c}=K_{5} \text {. }
$$

Adding, the total weight, $W$, may be written

$$
W=K_{1}+K_{5}+K_{0}+K_{2} E+\frac{K_{3}}{E^{2}}+\frac{K_{4}}{E} .
$$

Strictly speaking, $\mathrm{K}_{5}$ is not a constant but is a function of voltage, since, if the voltage were very low, all of the conductors might have to be larger than the smallest size having sufficient mechanical strength, whereas if the voltage were sufficiently high, a large proportion of the conductors might be of the smallest practicable size. However, as will be shown later, large changes in the values of $K_{3}$ and $K_{4}$, within the range of reasonable designs, have little effect on the final result. If $K_{5}$ for any one plane does change with voltage, most of the effect of the change is compensated by corresponding changes in $K_{3}$ and $K_{4}$.

Differentiating eq 6 , putting the derivative equal to zero, and solving the resulting equation gives the voltage designated $E_{0}$. This voltage will be called the optimum voltage, because it is the voltage for which the system has a minimum weight.

or

$$
\frac{d W}{d E}=K_{2}-\frac{2 K_{3}}{E^{3}}-\frac{K_{4}}{E^{2}}=0
$$

$$
E_{0}\left(K_{2} E_{0}^{2}-K_{6}\right)=2 K_{3},
$$


which gives the optimum voltage for assumptions $3 \mathrm{~A} 1,3 \mathrm{~A} 2$, and $3 \mathrm{~A} 3$. If

$$
W_{v c}=K_{5}=0,
$$

eq 6 satisfies assumptions $3 \mathrm{~B} 1$ and $3 \mathrm{~B} 2$, provided $W_{w}$ is the total weight of conductor and $W_{0}$ the total weight of insulation and conduit The optimum voltage is again given by eq 8 , which is written

$$
E_{0}\left(K_{2} E_{0}^{2}-K_{4}^{\prime}\right)=2 K_{3}^{\prime},
$$

the constants $K_{3}$ and $K_{4}$ being written as $K_{3}^{\prime}$ and $K_{4}^{\prime}$ to distinguish the assumptions under $3 \mathrm{~B} 1$ and $3 \mathrm{~B} 2$.

If $W_{w c c}=K_{5}=0$ and $K_{4}=0$, this means that the total weight of cable and conduit changes inversely with the voltage squared. This was assumption $3 \mathrm{C} 1$ and eq 8 may be written

where

$$
E_{0}=\left(\frac{2 K_{3}^{\prime}}{K_{2}}\right)^{1 / 3}=A\left(K_{3}^{\prime}\right)^{1 / 3},
$$

$$
A=\left(\frac{2}{K_{2}}\right)^{1 / 3} .
$$

Since $W_{\imath}$ in eq 3 now designates the total weight in accordance with assumption $3 \mathrm{C} 1$, the constant $K_{3}$ is designated by $K_{3}^{\prime}$.

The constant $K_{1}$, which designates the weight of the generator, motors, and other parts is of no importance in determining either the shape of the curve or the optimum voltage and in the computations which follow will be omitted. The weight of the system without the generator, motor, lights, and other equipment whose weight is independent of voltage, except that designated by $K_{5}$, will be designated $W^{\prime}$. Eq 6 may then be written for the weight of battery, cable, and conduit according to assumptions $3 \mathrm{~A} 1,3 \mathrm{~A} 2,3 \mathrm{~A} 3 ; 3 \mathrm{~B} 1$, $3 \mathrm{~B} 2$; and $\mathrm{C} 1$.

Assumptions 3A1, 3A2, 3A3:

$$
W^{\prime}=K_{0}+K_{2} E+\frac{K_{3}}{E^{2}}+\frac{K_{4}}{E}+K_{5} .
$$

Assumptions 3B1 and 3B2:

Assumption 3C1:

$$
W^{\prime}=K_{0}+K_{2} E+\frac{K_{3}^{\prime}}{E^{2}}+\frac{K_{4}^{\prime}}{E} .
$$

$$
W^{\prime}=K_{0}+K_{2} E+\frac{K_{3}^{\prime}}{E^{2}} .
$$

\section{COMPUTATIONS}

In table 1 are shown the results of computations for a number of airplanes which, if equipped with 12 -volt systems, would require the combined weights of cable and conduit shown in the first column of the table. Columns 2 and 3 of the table show the weights of conductor and conduit and insulation, respectively, on the assumption that 70 percent of the combined weight is that of the conductor. The optimum voltage for each plane, as calculated from eq 11, appears in column 4. In these computations the battery constant, $K_{2}$, is taken as 1 for all weights of cable and conduit. If it is assumed that the airplane with the greatest weight of cable and conduit requires the 
largest battery, then $K_{2}$, if it changes at all, will probably increase with increase in weight of cable and conduit. An inspection of the equations shows that with an increase in $K_{2}$ the optimum voltage will be decreased, and if $K_{2}$ increases with the size of the plane the optimum voltage for the heavier units will more nearly agree with that for the lighter units than is indicated by the values in table 1 . Using the single value $K_{2}=1$ for all weights of cable and conduit, gives the maximum difference between the optimum voltages for the large and small units.

TABLE 1.-Optimum voltage for different weights of cables and conduits

\begin{tabular}{|c|c|c|c|c|c|c|c|}
\hline \multirow{2}{*}{$\begin{array}{l}\text { Weight of cable and conduit of 12-volt } \\
\text { system }\end{array}$} & \multirow{2}{*}{$\begin{array}{l}\text { Weight } \\
\text { of con- } \\
\text { ductor }\end{array}$} & \multirow{2}{*}{$\begin{array}{l}\text { Weight of } \\
\text { conduit } \\
\text { and insu- } \\
\text { lation }\end{array}$} & \multicolumn{3}{|c|}{$\begin{array}{l}\text { Optimum voltage } \\
\text { equation }\end{array}$} & \multirow{2}{*}{$\begin{array}{l}\text { Increase in } \\
\text { weight if } \\
24 \text { volts is } \\
\text { used in- } \\
\text { stead of } \\
\text { optimum } \\
\text { voltage } \\
\text { given by } \\
\text { eq } 11\end{array}$} & \multirow{2}{*}{$\begin{array}{l}\text { Increase in } \\
\text { weight if } \\
12 \text { volts is } \\
\text { used in- } \\
\text { stead of } \\
\text { optimum } \\
\text { voltage } \\
\text { given by } \\
\text { eq } 11\end{array}$} \\
\hline & & & 11 & 10 & 8 & & \\
\hline 1 & 2 & 3 & 24 & b 5 & - 6 & 7 & 8 \\
\hline $\begin{array}{c}{ }^{2} \\
10\end{array}$ & $\begin{array}{r}\text { lb } \\
7 \\
14 \\
35 \\
49 \\
70 \\
105 \\
140 \\
210 \\
280 \\
350\end{array}$ & $\begin{array}{r}l b \\
3 \\
6 \\
15 \\
21 \\
30 \\
45 \\
60 \\
90 \\
120 \\
150\end{array}$ & $\begin{array}{l}v \\
14 \\
18 \\
24 \\
27 \\
30 \\
35 \\
38 \\
44 \\
49 \\
52.5\end{array}$ & $\begin{array}{l}v \\
13 \\
18 \\
24 \\
28 \\
32 \\
37 \\
41 \\
48 \\
54 \\
59\end{array}$ & $\begin{array}{l}v \\
12.5 \\
16 \\
22.5 \\
25 \\
29 \\
33 \\
37 \\
43 \\
48 \\
53\end{array}$ & $\begin{array}{r}\text { lb } \\
5 \\
2 \\
0 \\
0 \\
3 \\
10 \\
15 \\
30 \\
50 \\
70\end{array}$ & lb $\begin{array}{r}1 \\
5 \\
25 \\
40 \\
65 \\
110 \\
155 \\
245 \\
340 \\
435\end{array}$ \\
\hline
\end{tabular}

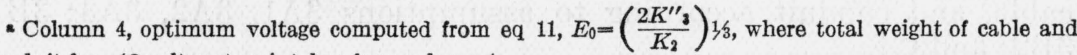
conduit for a 12-volt system is taken from column 1.

bolumn 5, optimum voltage computed from eq $10, E_{0}\left(K_{2} E^{2}{ }_{0}-K^{\prime}{ }_{4}\right)=2 K^{\prime}{ }_{3}$, where the constants $K^{\prime}{ }_{3}$ and $K^{\prime}{ }_{4}$ are computed from columns 2 and 3 , respectively.

- Column 6, optimum voltage computed from eq $8, E_{0}\left(K_{2} E^{2}{ }_{0}-K_{4}\right) 2{ }_{3}$, where $K_{3}$ is obtained by taking 80 percent of the weight of conductor given in column 2 and 70 percent of the weight given in column 3.

The other constant, $K^{\prime \prime}{ }_{3}$, appearing in eq 11 was calculated for each plane from eq 3 , using for $W_{w}$ the combined weight of cable and conduit for a 12-volt system, since, for the conditions under which $K_{3}=K^{\prime \prime}{ }_{3}$, the value of $W_{w}$ is the combined weight of cable and conduit shown in the first column of table 1.

In column 5 are given the optimum voltages calculated from eq 10. The constants $K^{\prime}{ }_{3}$ and $K^{\prime}$ appearing in this equation were calculated for each airplane from eq 3 and 4 , respectively, using for $W_{w}$ the values from column 2 , and for $W_{c}$ those from column 3 of table 1 , since for the conditions under which $K_{3}=K^{\prime}{ }_{3}$ and $K_{4}=K^{\prime}{ }_{4}$, the value of $K_{5}=0$.

The optimum voltages in column 6 were calculated from eq 8 , with the assumption that the part of the weight which is independent of voltage consists of 20 percent of the weight of conductor and 30 percent of the weight of insulation and conduit in the 12-volt system.

The table indicates that although the assumptions leading to eq 8 , 10 , and 11 are different, the calculated optimum voltages are nearly the same. The reason for this may be seen by referring to figures 2 and 3 . In figure 2 are 10 curves, showing for a number of voltages the total weight of battery, cable, and conduit necessary to replace 


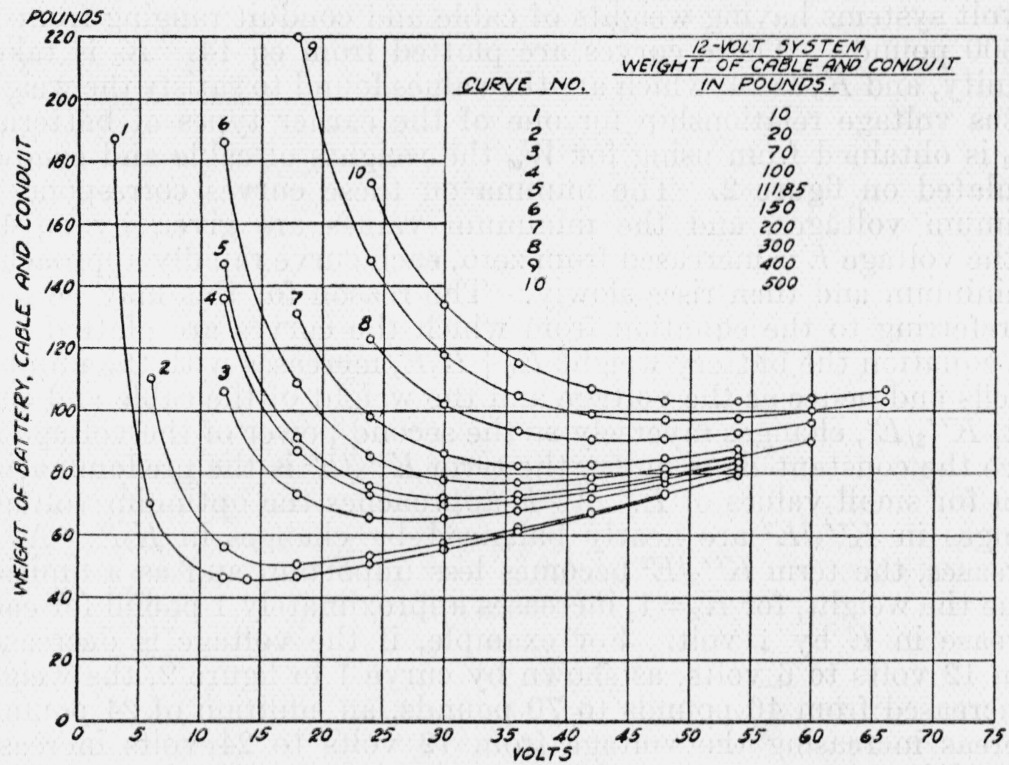

FIGURE 2.

Curves showing the change in weight of battery, cable and conduit with voltage. Values computed from equation 14.

$W_{b}=24+E$.

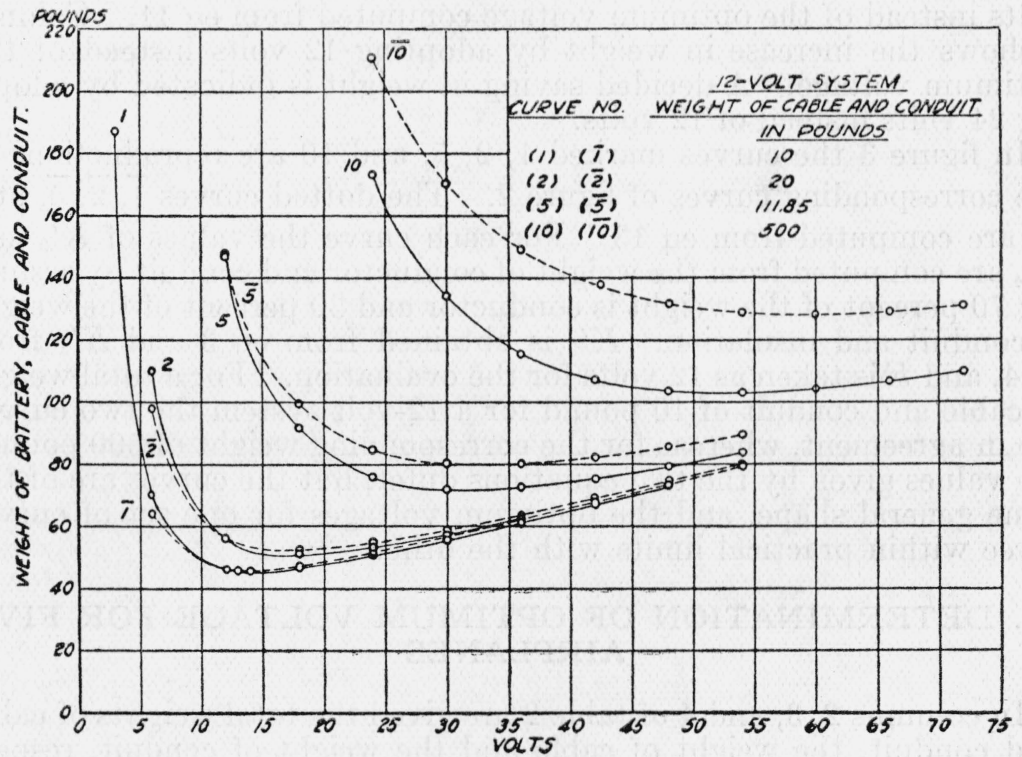

FIgURE 3.

Curves showing the change in weight of battery, cable and conduit with voltage. Values indicated by solid lines are plotted from equation 14. Values indicated by dotted lines are plotted from equation 13. 
12 -volt systems having weights of cable and conduit ranging from 10 to 500 pounds. These curves are plotted from eq $14 . K_{2}$ is taken as unity, and $K_{0}$ as 24, which are the values found to satisfy the weight versus voltage relationship for one of the earlier types of batteries. $K^{\prime \prime}{ }_{3}$ is obtained from using for $W_{w}$ the weights of cable and conduit tabulated on figure 2. The minima on these curves correspond to optimum voltages, and the minimum values are given by eq 11 . As the voltage $E$ is increased from zero, each curve rapidly approaches a minimum and then rises slowly. The reason for this may be seen by referring to the equation from which the curves are plotted. In this equation the battery weight $K_{0}+K_{2} E$, increases with the number of cells and hence as the voltage and the weight of the cable and conduit, $K^{\prime \prime}{ }_{3} / E^{2}$, changes inversely as the second power of the voltage $E$. Since the constant $K_{2}$ is unity, the term $K^{\prime \prime}{ }_{3} / E^{2}$ is the predominating term for small values of $E$. As $E$ approaches the optimum voltage, changes in $K^{\prime \prime}{ }_{3} / E^{2}$ are nearly balanced by changes in $K_{2} E$. $\mathrm{As} E$ increases, the term $K^{\prime \prime}{ }_{3} / E^{2}$ becomes less important and as a limiting. value the weight, for $K_{2}=1$, increases approximately 1 pound for each increase in $E$ by 1 volt. For example, if the voltage is decreased from 12 volts to 6 volts, as shown by curve 1 in figure 2 , the weight is increased from 46 pounds to 70 pounds, an addition of 24 pounds, whereas increasing the voltage from 12 volts to 24 volts increases the weight to 50 pounds, an increase of only 4 pounds; but a further increase of 12 volts increases the weight 11 pounds. Since the optimum voltage is 14 with a total weight of 45 pounds, increasing the voltage to 24 increases the weight only 5 pounds.

Column 7 of table 1 shows the increase in weight by adopting 24 volts instead of the optimum voltage computed from eq 11. Column 8 shows the increase in weight by adopting 12 volts instead of the optimum voltage. A decided saving in weight is indicated by adopting 24 volts instead of 12 volts.

In figure 3 the curves marked $1,2,5$, and 10 are reproductions of the corresponding curves of figure 2 . The dotted curves $\overline{1}, \overline{2}, \overline{5}$, and $\overline{10}$ are computed from eq 13. For each curve the values of $K^{\prime}{ }_{3}$ and $K^{\prime}{ }_{4}$ are computed from the weight of conductor and conduit by assuming 70 percent of the weight is conductor and 30 percent of the weight is conduit and insulation. $K_{3}^{\prime}$ is obtained from eq 3 and $K^{\prime}{ }_{4}$ from eq 4 , and $E$ is taken as 12 volts for the evaluation. For a total weight of cable and conduit of 10 pound for a 12-volt system the two curves are in agreement, whereas for the corresponding weight of 500 pounds the values given by the two equations differ, but the curves are of the same general shape, and the optimum voltages for one set of curves agree within practical limits with the other.

\section{DETERMINATION OF OPTIMUM VOLTAGE FOR FIVE AIRPLANES}

In columns 2,3 , and 4 of table 2 are given the total weights of cable and conduit, the weight of cable and the weight of conduit, respectively, for five different types of airplanes. Since it is difficult to estimate the weight of insulation on the cable, the constant $\mathrm{K}_{3}^{\prime}$ is obtained by using the weight of the cable as the weight of the conductor, and $K^{\prime}{ }_{4}$ is calculated from the weight of the conduit. $K^{\prime \prime}{ }_{3}$ is 
based on the total weight given in column 2, using eq 3. Substituting these values in eq 10 and 11 , with $K_{2}$ taken as 0.85 , the optimum voltages are obtained. Columns 6 and 7 show the increase in weight if 12 volts is used instead of the optimum voltage. In columns 8 and 9 are given the increases in weight which would result from using 24 volts instead of the optimum voltage. The agreement between these two columns indicates that it is not important whether the optimum voltages are computed from eq 13 or 14 for the range of weights covered by these airplanes. The 10 curves in figure 4 show the change in combined weight of battery, cable, and conduit with voltage, using eq 14 and 13.

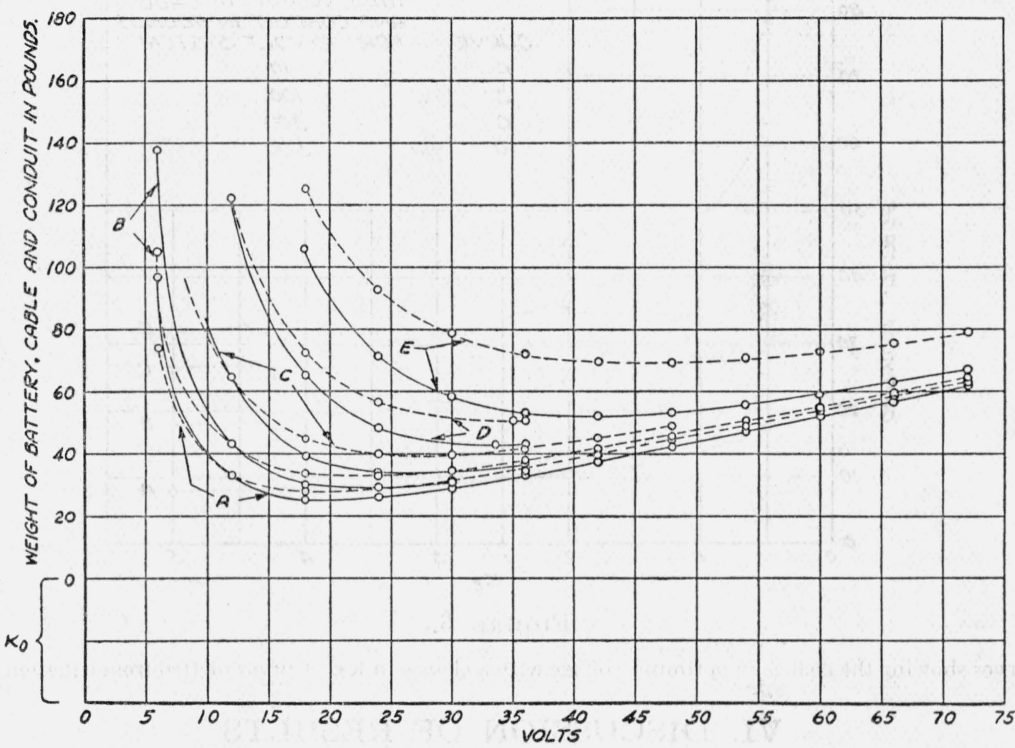

FigURe 4.

Curves showing the change in weight of equipment with voltage for the five airplanes listed in table 2. Curves with solid lines computed from equation (14). Curves with dotted lines computed from equation (13).

TABLE 2.-Optimum voltages for five types of airplanes

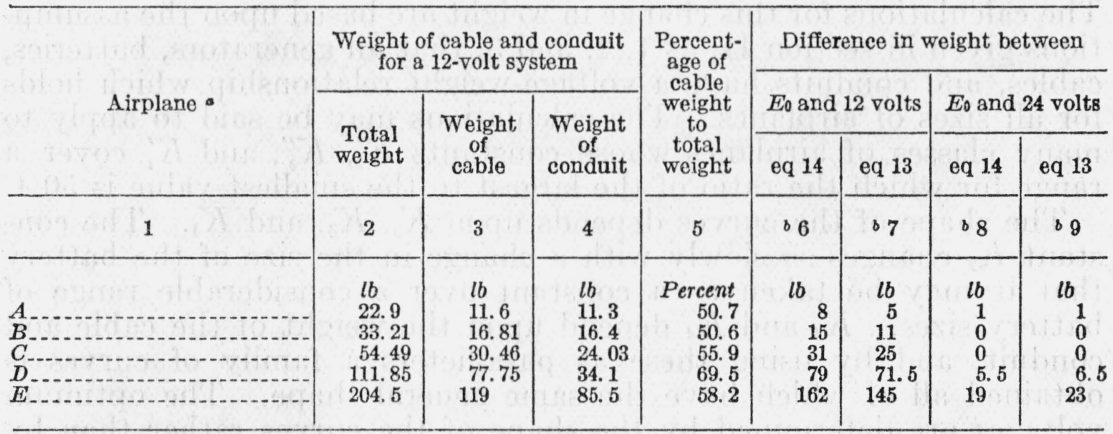

a Airplane $A$ is a single-seat type; $B$, a two-seat type; $C$, a three-seat type; $D$, a small twin-engine type; and $E$, a large twin-engine type.

$b$ Columns 6 and 7 show the difference between the weight of cable and conduit for the optimum voltage and that for 12 volts. Columns 8 and 9 show the difference between the weight of cable and conduit for the optimum voltage and that for 24 volts. Thus, if 24 volts is used instead of 12 , airplane $C$ will save 31 pounds according to columns 6 and 8 , and 25 pounds according to columns 7 and 9. 


\section{CHANGES IN OPTIMUM VOLTAGES WITH $K_{2}$}

The four curves in figure 5 show that as $K_{2}$ increases the optimum voltage decreases. The values are computed from eq 10 , because this equation indicates greater changes in voltage with $K_{2}$ than eq 8 or 11. The values for the constants $K_{3}^{\prime}$ and $K_{4}^{\prime}$ were computed from the weights for a 12 -volt system by taking 70 percent of the combined weight as the weight of the conductor and 30 percent of the total weight as the weight of the insulation and conduit.

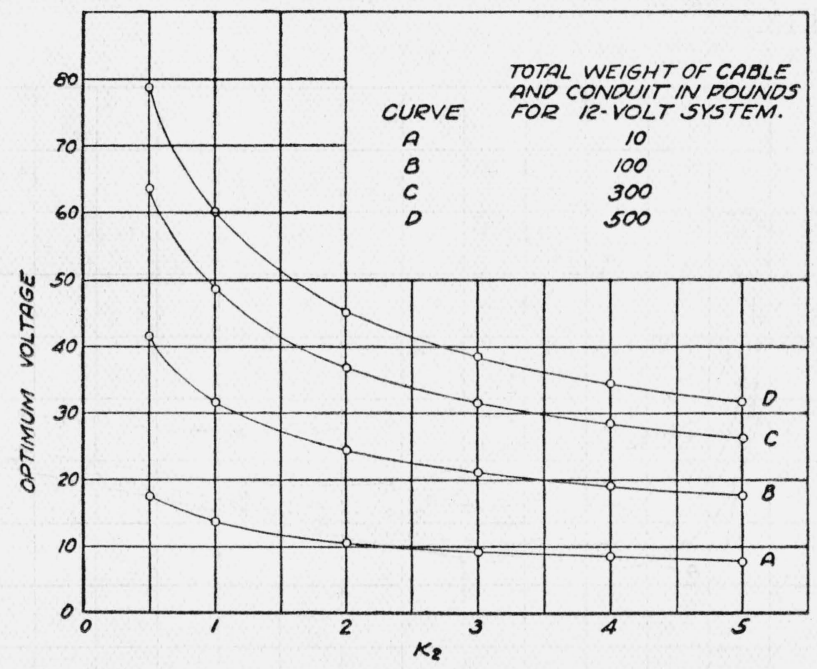

Figure 5.

Curves showing the change in optimum voltage with a change in $\mathbf{K}_{2}$. Curves plotted from equation 10 .

\section{DISCUSSION OF RESULTS}

In determining the optimum voltage for a large number of airplanes, some of which are in use and some of which are not at this time designed, it was necessary to make broad but reasonable assumptions as to how the weight of electric equipment will change with voltage. The calculations for this change in weight are based upon the assumptions given in section II, as 1,2 , and 3 , that all generators, batteries, cables, and conduits have a voltage-weight relationship which holds for all sizes of airplanes. The calculations may be said to apply to many classes of airplanes whose constants $K_{3}^{\prime}, K_{3}^{\prime \prime}$, and $K_{4}^{\prime}$ cover a range for which the ratio of the largest to the smallest value is 50:1.

The shape of the curves depends upon $K_{2}, K_{3}$, and $K_{4}$. The constant $K_{2}$ changes so slowly with a change in the size of the battery that it may be taken as a constant over a considerable range of battery sizes. $K_{3}$ and $K_{4}$ depend upon the weight of the cable and conduit, and by using these as parameters a family of curves is obtained all of which have the same general shape. The optimum voltages are determined by the shape of the curves rather than by their positions, and since the change in weight with voltage is slow in the neighborhood of the optimum voltage, the curves may be said 
to have a minimum region. It is because of this slow rate of change in weight with voltage that such good agreement is obtained for the wide range of values when using the three diverse assumptions $3 \mathrm{~A} 1$, $3 \mathrm{~A} 2,3 \mathrm{~A} 3 ; 3 \mathrm{~B} 1,3 \mathrm{~B} 2$; and $3 \mathrm{C} 1$.

The assumption that the weight of the cable is 70 percent of the total weight of cable and conduit was true for only one airplane, as shown in column 5 of table 2 . However, as shown in figure 3 , the curves plotted from eq 14 for the smaller weight of cable and conduit are almost identical with the curves plotted from eq13, notwithstanding the difference in assumptions.

Curves 5 and $\overline{5}$ for all practical purposes are similar, although the weights are slightly different. For larger planes, such as indicated by the two curves 10 and $\overline{10}$, a separate auxiliary power unit will probably be necessary, and in this type of plane more than one voltage will be available. It will be noted that the shape of the two curves is nearly the same, and while there is a difference in weight, the selection of an optimum voltage from curve 5 will result in only a fraction of a pound change in weight over what would be the optimum weight on the basis of $\overline{5}$.

The curves are not plotted for eq 8 , since using eq 8 , is the same as taking a fractional part of the weight of wire and conduit and substituting these values in eq 10 . Practically, this is the same as making the computations for a smaller airplane.

Referring to eq 11, it is seen that the optimum voltage depends upon the weight of cable and conduit and the constant $K_{2}$. This constant for the two larger batteries, for which curves are shown in figure 1 , is for all practical purposes the same, since it changes less by doubling the capacity than the uncertainty of the other factors entering into this equation. This means that to a reasonable approximation the optimum voltage is independent of the watt-hour capacity of the battery, which seems somewhat paradoxical. In practice, this means that once the optimum voltage is determined, the discharge rate and output of the battery may be changed without affecting the optimum voltage, notwithstanding the total weight of the battery is changed by changing the output.

The increase in optimum voltage with a decrease in $K_{2}$ suggests that with more efficient battery construction a higher operating voltage is desirable. A recalculation of the values, using $K_{2}=0.85$ instead of 1 , would indicate higher optimum voltages in columns 4 , 5 , and 6 of table 1 .

The values given in table 2 are for $K_{2}=0.85$ and indicate that 24 volts is the optimum voltage for the single-engine type. For the twin-engine type, the voltage should be higher, but if a single voltage is to be selected for all classes of planes, 24 volts seems to place the additional weight only in the larger planes, which in most cases should be able to take care of this weight.

\section{CONCLUSIONS}

Stated briefly, the equations indicate the following:

1. Although the computed weight of the system will change, the shape of the curves will be approximately the same whether the assumptions 1 and 2 are combined with $3 \mathrm{~A} 1,3 \mathrm{~A} 2,3 \mathrm{~A} 3 ; 3 \mathrm{~B} 1,3 \mathrm{~B} 2$; and 
$3 \mathrm{C} 1$, at least for the range of weights covered by table 1 . The curves may be used to select the optimum voltage which will give approximately the minimum total weight in each case. The capacity of the battery selected will affect the absolute weight of this system, but the optimum voltage should not be greatly changed.

2. For airplanes of the single-engine type, standardization on 24 volts seems to meet the requirements for a large number of airplanes, and this voltage is in agreement with that used by several European countries. For airplanes having 10 pounds of cable and conduit or less, there may be an increase in weight of 5 pounds or more if one of the existing types of 24 -volt batteries is used. If batteries having a smaller increase in weight with increasing number of cells are developed, the penalty for this choice of higher voltage will be less.

3 . For large airplanes, where auxiliary power plants are used, it may be desirable to supplement the standard 24-volt generator-battery system with a higher voltage a-c or d-c system without battery.

The authors thank E. F. Mueller for his many helpful suggestions. Washington, August 4, 1939. 